\title{
The Diagnosis and Treatment of Ectopic Pregnancy
}

\author{
Florin-Andrei Taran, Karl-Oliver Kagan, Markus Hübner, Markus Hoopmann, \\ Diethelm Wallwiener, Sara Brucker
}

\section{SUMMARY}

Background: Extrauterine pregnancy is a complication of the first trimester of pregnancy that arises in $1.3-2.4 \%$ of all pregnancies.

Methods: This review is based on articles and guidelines retrieved by a selective PubMed search.

Results: The presentation of extrauterine pregnancy is highly variable, ranging from an asymptomatic state, to pelvic pain that is worse on one side, to tubal rupture with hemorrhagic shock. $75 \%$ of tubal pregnancies can be detected by transvaginal ultrasonography. In patients with a vital extrauterine pregnancy, the human chorionic gonadotropin concentration generally doubles within 48 hours. Laparoscopy is the gold standard of treatment. Two randomized, controlled trials comparing organ-preserving treatment with ablative surgery revealed no significant difference in pregnancy rates after the intervention, but precise details of the surgical procedures were not provided, and long-term fertility data are lacking. Methotrexate therapy should be used only for strict indications.

Conclusion: Further randomized, controlled trials with longer follow-up will be needed to answer currently open questions about the potential for individualized surgical treatment and the proper role of pharmacotherapy.

\section{Cite this as:}

Taran FA, Kagan KO, Hübner M, Hoopmann M, Wallwiener D, Brucker S: The diagnosis and treatment of ectopic pregnancy. Dtsch Arztebl Int 2015; 112: 693-704. D0l: 10.3238/arztebl.2015.0693

\begin{abstract}
xtrauterine (ectopic) pregnancy is the implantation of a fertilized oocyte outside the uterine cavity. Tubal pregnancy (Figure 1) is only one kind of extrauterine pregnancy, albeit the most clinically significant; non-tubal and heterotopic extrauterine pregnancies are rare $(1-3 \%)(1)$.

Extrauterine pregnancy is a complication of the first trimester of pregnancy that carries major morbidity and mortality. Even today, it accounts for as much as $6 \%$ of pregnancy-associated mortality $(1,2)$. Improved diagnostic and therapeutic methods have made maternal death from extrauterine pregnancy rare as a global phenomenon $(0.05 \%)$, yet the quality of diagnosis and treatment of this condition is not uniform $(2,3)$. Despite the availability of minimally invasive surgical methods, delayed diagnoses and errors in acute treatment and follow-up care still make ruptured extrauterine pregnancy a part of everyday life in obstetrics and gynecology.
\end{abstract}

\section{Learning objectives}

After reading this article, the reader should

- know the epidemiology and risk factors of extrauterine pregnancy,

- understand its main symptoms and signs and its diagnostic evaluation, and

- be familiar with its medical and surgical treatment.

\section{Methods}

We carried out a selective search in the PubMed database for pertinent articles and guidelines published in English from 1990 to April 2015, using the following search terms: "ectopic pregnancy" alone or in combination with "diagnosis," "epidemiology," "laparoscopic surgery," "medical treatment," "methotrexate,"

\footnotetext{
Morbidity and mortality

Extrauterine pregnancy is a complication of the first trimester of pregnancy that carries major morbidity and mortality, accounting for up to $6 \%$ of pregnancy-associated mortality even today.
} 


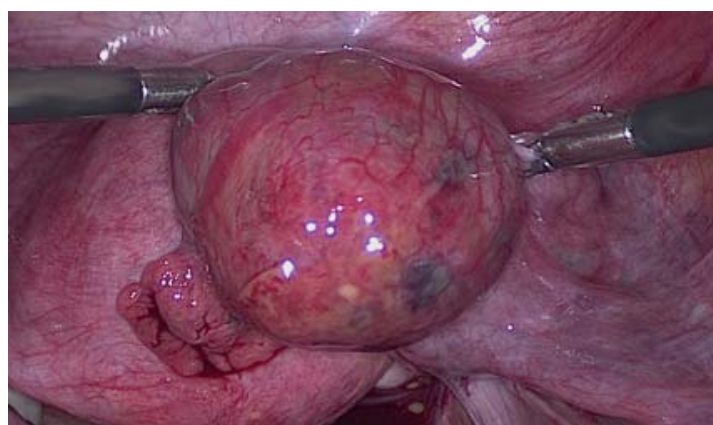

Figure 1: Right tubal pregnancy in week $6+5$ of gestation.

"pregnancy of unknown location," "rate," "risk factors," "salpingectomy," "salpingotomy," "surgical treatment," and "treatment."

\section{Epidemiology}

It has been reported that $1.3-2.4 \%$ of all pregnancies are extrauterine. The true frequency cannot be estimated any more accurately than this, because statistics generally reflect only cases treated in the hospital and with surgery (4). In the mid-twentieth century, it was estimated that $0.4 \%$ of all pregnancies in the USA were extrauterine; recent data show a current figure higher than $1.4 \%$ (1). In Germany today, there are an estimated 20 extrauterine pregnancies for every 1000 live births (4). The rising frequency of (diagnosed) extrauterine pregnancies is due to a number of factors, including:

- the increased utilization of assisted reproductive technology,

- the increasing number of operations performed on the fallopian tubes,

- rising maternal age, and

- more sensitive diagnosis (2).

\section{Pathogenesis}

Extrauterine pregnancy is of multifactorial origin. Up to half of all women with an extrauterine pregnancy have no recognized risk factors for it (5). The postulated mechanisms include anatomical and/or functional tubal obstruction, impaired tubular motility and ciliary dysfunction, and molecular chemotactic factors that stimulate and promote tubal implantation (5).

\section{Risk factors}

\section{Factors conferring a high risk [odds ratio $(\mathrm{OR})>4.0$ ]}

Prior tubal surgery or a prior tubal pregnancy are the most important risk factors for tubal pregnancy $(6,7)$ (Table 1). Sterilization is a very effective method of contraception; nevertheless, if a woman becomes pregnant despite having undergone a putatively sterilizing procedure, extrauterine pregnancy must be considered as a possibility, as about $30 \%$ of pregnancies after sterilization are extrauterine (8). The cumulative 15 -year risk of tubal pregnancy is 2.9 per 1000 sterilizations (9). The risk of tubal pregnancy is higher after electrocoagulation of the fallopian tubes, because of tubal recanalization and/or the formation of a utero-/ tuboperitoneal fistula (8).

Women who use an intrauterine device are at lower risk of ectopic pregnancy than those who use no contraception. If woman using an intrauterine device is nonetheless found to be pregnant, extrauterine pregnancy should be ruled out, as $50 \%$ of such pregnancies are extrauterine $(5,10)$.

\section{Factors conferring a moderately elevated risk (OR > 2.0)}

Elevated rates of extrauterine pregnancy have been found among women taking hormones (clomifene) to treat infertility, although the increased prevalence of tubal pathology and prior surgical treatments in this population are obvious confounding variables (1). Assisted reproductive technology (ART) has also been reported to elevate the risk of an extrauterine pregnancy from $0.025 \%$ (the value in the general population) to $1 \%$ among women who have undergone in vitro fertilization (11). The incidence of extrauterine pregnancy after ART seems to have fallen somewhat in recent years (12).

Women with an active or prior ascending infection with Chlamydia trachomatis or Neisseria gonorrhoeae are at an elevated risk of extrauterine pregnancy. Other types of intra-abdominal infection, e.g., appendicitis, can also raise the risk (13).

\section{Factors conferring a mildly elevated risk $(\mathrm{OR}<2.0)$}

The highest incidence of extrauterine pregnancy is between the ages of 35 and 45, perhaps because of the cumulative effect of multiple risk factors over time (5).

\section{Clinical features, course, and differential diagnosis}

Extrauterine pregnancy may be wholly asymptomatic (intact tubal pregnancy [intact fallopian tube and embryo,

\section{Pathogenesis}

Extrauterine pregnancy is of multifactorial origin. Up to half of all women with an extrauterine pregnancy have no recognized risk factors for it.

\section{Factors conferring a high risk of extrauterine pregnancy}

Prior tubal surgery and prior tubal pregnancy are the main risk factors for tubal pregnancy. 
Risk factors for extrauterine pregnancy $(6,7)^{*}$

\begin{tabular}{|c|c|c|}
\hline \multicolumn{3}{|l|}{ Factors } \\
\hline $\begin{array}{l}\text { High risk } \\
(\mathrm{OR}>4.0)\end{array}$ & $\begin{array}{l}\text { Moderately elevated risk } \\
(\mathrm{OR}>2.0)\end{array}$ & $\begin{array}{l}\text { Mildly elevated risk } \\
(\mathrm{OR}<2.0)\end{array}$ \\
\hline $\begin{array}{l}\text { - prior tubal surgery } \\
\text { adjusted OR: } 4.0 \text { (2.6-6.1); OR: 4.7-21.0 }\end{array}$ & $\begin{array}{l}\text { - sterility } \\
\text { adjusted OR: } 2.1-2.7 ; \text { OR: 2.5-21.0 }\end{array}$ & $\begin{array}{l}\text { - age over } 40 \text { years } \\
\text { (OR: } 1.4-6.1 \text { ) }\end{array}$ \\
\hline $\begin{array}{l}\text { - prior extrauterine pregnancy } \\
\text { (OR: } 6.0-11.5)\end{array}$ & $\begin{array}{l}\text { - current or prior ascending infection } \\
\text { adjusted OR: } 3.4(2.4-5.0) ; \text { OR: } 2.5-3.7\end{array}$ & \\
\hline $\begin{array}{l}\text { - sterilization } \\
\text { (OR: } 4.9-18.0)\end{array}$ & $\begin{array}{l}\text { - cigarette smoking } \\
\text { adjusted OR: } 1.5 \text { (1.1-2.2); OR: 2.3-2.5 }\end{array}$ & \\
\hline $\begin{array}{l}\text { - use of intrauterine device } \\
\text { adjusted OR: } 2.4 \text { (1.2-4.9); OR: 4.2-45.0 }\end{array}$ & - more than one sexual partner (OR: 2.1-2.5) & \\
\hline $\begin{array}{l}\text { - intrauterine exposure to diethylstilbestrol } \\
\text { (OR: } 2.4-13.0 \text { ) }\end{array}$ & $\begin{array}{l}\text { - tubal pathology } \\
\text { adjusted OR: } 3.7 \text { (1.2-4.8); OR: 2.5-3.5 }\end{array}$ & \\
\hline
\end{tabular}

*adjusted for prior ascending infection, cigarette smoking, educational level, and region of origin; OR, odds ratio.

perhaps with discernible cardiac function]), or it may present with pelvic pain that is worse on one side (tubal abortion) or with severe hemorrhagic shock (tubal rupture). Extrauterine pregnancies are most commonly diagnosed in the 6th through 9th week of gestation; most patients present with nonspecific complaints (2).

The symptom triad of mild vaginal spotting in the first trimester, aching pelvic pain, and secondary amenorrhea may indicate extrauterine pregnancy but can also arise in an intact intrauterine pregnancy or as a consequence of early miscarriage (2). Further suggestive manifestations include abdominal pain radiating to the shoulder(s), abdominal guarding or an acute abdomen, pain on displacement of the vaginal portion of the cervix, hemorrhagic shock/hemodynamic instability (dyspnea, hypotension, tachycardia), and syncope. The adnexum on the affected side is often enlarged and tender (8). In view of the complexity of the associated findings, various other entities in the differential diagnosis need to be ruled out whenever an extrauterine pregnancy is suspected: cystic or solid adnexal tumors causing peritoneal irritation (especially by torsion or rupture), adnexal infection (e.g., tubo-ovarian abscess), appendicitis, or ovarian hyperstimulation syndrome with ascites.

\section{The typical time of diagnosis}

Extrauterine pregnancies are most commonly diagnosed in the $6^{\text {th }}$ through $9^{\text {th }}$ week of gestation. Most patients present with nonspecific complaints.

\section{Diagnosis}

\section{Pregnancy of unknown location}

Ectopic pregnancy is to be distinguished from another entity called "pregnancy of unknown location" (PUL). Both are characterized by the lack of visualization of an intrauterine pregnancy on ultrasonographic examination. The initial ultrasound study during pregnancy, depending on its timing and on the experience of the examiner, often does not yet clearly reveal an intrauterine pregnancy (14); an extrauterine pregnancy turns out to be present in $7-20 \%$ of such cases (14). The differential diagnosis includes an intact early intrauterine pregnancy that cannot yet be seen by ultrasound and an early miscarriage. The imaging studies, individual clinical features, and course of the human chorionic gonadotropin (hCG) level point to the correct diagnosis (14).

An intact early intrauterine pregnancy is present in some $30-50 \%$ of cases with unclear findings. It should be borne in mind that even an intrauterine pregnancy sometimes cannot be seen by ultrasonography if the hCG level is below $1000 \mathrm{IU} / \mathrm{L}$. When the hCG level is higher than this, an intrauterine pregnancy reveals itself as an eccentrically positioned, hyperechogenic ring structure. If an embryo or yolk sac is seen, then an intrauterine pregnancy is definitely present. If only an empty, round 

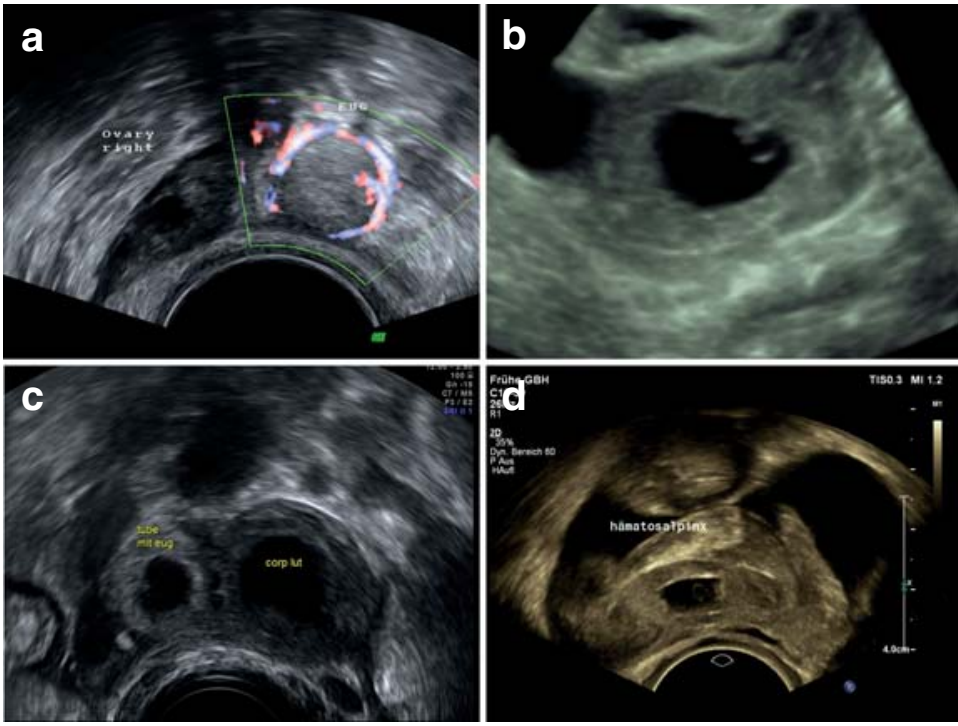

Figure 2: Ultrasonographic findings in four different cases of tubal pregnancy.

a) Right tubal pregnancy in week $6+1$ of gestation, with blob sign and circular Doppler ultrasonographic signal.

b) Vital left tubal pregnancy in week $6+0$ of gestation, with a yolk sac and an embryo measuring $2 \mathrm{~mm}$ (crown-rump) with detectable cardiac activity (shown in 3D-VCl mode)

c) Right tubal pregnancy in week $5+3$ of gestation, with bagel sign; note the difference in echogenicity compared to the cystic corpus luteum.

d) Right tubal pregnancy within a hematosalpinx; abundant free fluid indicating hematoperitoneum.

structure is seen, it may be a pseudogestational sac associated with an ectopic pregnancy. Pseudogestational sacs appear as a small collection of fluid in the uterine cavity and are thus not eccentrically located; they are generally not round, and they are never associated with a yolk sac or embryonic structures.

About half of all early miscarriages are associated with a pregnancy of unknown location. The endometrial thickness, as measured by ultrasound, is not correlated with the diagnosis of early complete abortion (15).

If a heterogeneous mass is seen in the tubal area, the likelihood of tubal pregnancy is higher. The visualization of a gestational sac (often including a yolk sac or embryonic structures) is required for the working hypothesis of a pregnancy of unknown location to be changed to a definitive diagnosis of tubal pregnancy (16). The following classification has been recommended in a consensus statement (16):
- definite ectopic pregnancy: extrauterine gestational sac with yolk sac and/or embryo

- probable ectopic pregnancy: heterogeneous mass in the adnexal area

- pregnancy of unknown location: no evidence of either an intrauterine or an extrauterine pregnancy

- probable intrauterine pregnancy: visualization of an intrauterine ring structure

- definite intrauterine pregnancy: intrauterine gestational sac with yolk sac and/or embryo.

\section{Tubal pregnancy}

In a study involving more than 5000 patients who had a total of 120 tubal pregnancies, Kirk et al. reported that $75 \%$ of tubal pregnancies were visible in the first transvaginal ultrasound examination (17).

A meta-analysis revealed that $88 \%$ of tubal pregnancies were identifiable by the combination of an absent intrauterine gestational sac with an adnexal mass. Pain on displacement of the vaginal portion of the cervix, an adnexal mass, and unilateral pelvic pain elevate the probability of tubal pregnancy by a factor of 2 to 5 (18).

A tubal pregnancy should be suspected if ultrasonography reveals gestational tissue in the adnexal area without any evidence of an intrauterine pregnancy. If a yolk sac or embryo is seen in the ectopic gestational tissue, the diagnosis of ectopic pregnancy is definitively confirmed. If a small fluid collection is seen in the uterine cavity, this may represent a pseudogestational sack. An echogenic fluid collection in Douglas' pouch is likely to be a hemorrhage, such as is seen in one-third to one-half of all cases of tubal pregnancy (14). If non-echogenic fluid covers the fundus or extends into Morison's pouch (between the liver and the right kidney), then the presumed diagnosis is a hemorrhage requiring therapeutic intervention (14). The adnexal mass is usually separate from the ovary, round, and echogenic (the "blob sign") (Figure 2a). Sometimes a classic gestational sac is seen, with an echogenic periphery and a round, nonechogenic interior ("bagel sign") (Figure 2c), which may contain the yolk sac or the embryo (Figure $2 b$ ). Hemorrhage can also be secondary to a hematosalpinx (Figure $2 d$ ). In a series of 219 tubal pregnancies, a round echogenic structure was seen in more than half, and a gestational sack without a yolk sac or embryo was seen in one-quarter (19).

The role of serum biochemical tests - The serum marker hCG plays an important role alongside

\section{Ectopic pregnancy}

If only an empty, round structure is seen, it may be a pseudogestational sac associated with an ectopic pregnancy. Pseudogestational sacs are not round, and they are never associated with a yolk sac or embryonic structures.

\section{Tubal pregnancy}

A tubal pregnancy should be suspected if ultrasonography reveals gestational tissue in the adnexal area without any evidence of an intrauterine pregnancy. 


\begin{tabular}{|c|c|c|c|c|}
\hline Trial & Design & $\begin{array}{l}\text { Trial arms } \\
\text { (number of patients) }\end{array}$ & Primary endpoint & Results \\
\hline $\begin{array}{l}\text { MTX or watchful waiting in } \\
\text { women with an EUP or PUL } \\
\text { and low hCG levels (26) }\end{array}$ & $\begin{array}{l}\text { Multicenter, prospective, } \\
\text { randomized, open-label }\end{array}$ & $\begin{array}{l}\text { Arm 1: single-dose MTX/(41) } \\
\text { Arm 2: watchful waiting /(32) }\end{array}$ & $\begin{array}{l}\text { Unevetful drop of hCG level } \\
\text { to below the threshold } \\
\text { of detection }\end{array}$ & $\begin{array}{l}\text { Arm 1: } 31 / 41(76 \%) \\
\text { Arm 2: } 19 / 32(59 \%) \\
\text { RR } 95 \% \text { Cl: } 1.3(0.9-1.8)\end{array}$ \\
\hline $\begin{array}{l}\text { Salpingotomy versus } \\
\text { salpingectomy for women } \\
\text { with TP (ESEP trial) (33) }\end{array}$ & $\begin{array}{l}\text { Multicenter, prospective, } \\
\text { randomized, open-label }\end{array}$ & $\begin{array}{l}\text { Arm 1: salpingotomy/(215) } \\
\text { Arm 2: salpingectomy/(231) }\end{array}$ & $\begin{array}{l}\text { Spontaneous, sustained } \\
\text { pregnancy }\end{array}$ & $\begin{array}{l}\text { Arm 1: } 60.7 \% \\
\text { Arm 2: } 56.2 \% \\
\text { Ratio of fertility rates }(95 \% \mathrm{Cl}) \\
1.06(0.81-1.38)\end{array}$ \\
\hline $\begin{array}{l}\text { Fertility after EUP } \\
\text { (DEMETER trial) (32) }\end{array}$ & $\begin{array}{l}\text { Multicenter, prospective, } \\
\text { randomized, open-label }\end{array}$ & $\begin{array}{l}\text { Arm 1/(207) } \\
\text { Arm 1a: organ-preserving } \\
\text { surgery plus MTX/(97) } \\
\text { Arm 1b: single-dose } \\
\text { MTX/(110) } \\
\text { Arm 2/(199) } \\
\text { Arm 2a: ablative surgery/(98) } \\
\text { Arm 2b: organ-preserving } \\
\text { /(101) surgery plus MTX }\end{array}$ & $\begin{array}{l}\text { Cumulative fertility rate } \\
\text { (intrauterine pregnancy) } \\
\text { in } 2 \text { years following treatment }\end{array}$ & $\begin{array}{l}\text { Arm 1 } \\
\text { Arm 1a: } 71 \% \\
\text { Arm 1b: } 67 \% \\
\text { HR 0.85 (0.59-1.22) } \\
\text { Arm 2 } \\
\text { Arm 2a: } 64 \% \\
\text { Arm 2b: } 70 \% \\
\text { HR 1.06 (0.69-1.63) }\end{array}$ \\
\hline
\end{tabular}

hCG, human chorionic gonadotropin; HR, hazard ratio; MTX, methotrexate; Cl, confidence interval; PUL, pregnancy of unknown location; RR, relative risk; TP, tubal pregnancy

ultrasonography in the diagnostic evaluation of pregnancy of unknown location. The course of the hCG level, rather than its absolute value, is determinative (20).

With a vital intrauterine pregnancy, the $\mathrm{hCG}$ level generally doubles within 48 hours, yet it sometimes rises by no more than $35 \%$ during this time even in normal cases (21).

About one-fifth of all cases of extrauterine pregnancy are associated with an hCG course resembling that of intrauterine pregnancy; in $10 \%$ of cases, the hCG course resembles that of an early miscarriage. The sensitivity and specificity of the 48-hour hCG ratio were found in a meta-analysis to be $74-100 \%$ and $28-97 \%$, respectively (20).

Ectopic pregnancy is generally associated with a rise in hCG by no more than $66 \%$, or a fall by no more than $13 \%$ from the baseline level, in 48 hours. A ratio lying within this range, along with an absolute $\mathrm{hCG}$ value above $1500 \mathrm{IU} / \mathrm{L}$ in the absence of any visualizable intrauterine pregnancy, can be taken as evidence for a probable ectopic pregnancy. This combined criterion is $92 \%$ sensitive and $84 \%$ specific $(22,23)$.

On the basis of these considerations, a riskestimation model was developed for the identification of high-risk cases among women with pregnancy of unknown location. With a risk cutoff set at $5 \%$, the model was found to be $84.7 \%$ sensitive (24). The progesterone level can be used in combination with the hCG value in order to rule out an intact pregnancy (25).

A single measurement of the progesterone level, however, was not found to be useful for the diagnosis of ectopic pregnancy (25).

\section{Treatment strategies Watchful waiting}

A single prospective randomized trial compared expectant management with the administration of a single dose of methotrexate to women with a pregnancy that was either extrauterine or of uncertain location (26) (Table 2). No significant difference was found between the two groups with respect to the uneventful decline of the serum hCG value under the threshold of detection (26). Because the available evidence is scant, watchful waiting cannot yet be adequately assessed and therefore cannot be recommended as a therapeutic option.

\section{Surgery}

The indications for surgery are listed in Table 3. The surgical treatment of tubal pregnancy consists either of an organ-preserving procedure or a salpingectomy (27).

\section{Serum biochemistry}

About one-fifth of all cases of extrauterine pregnancy are associated with an hCG course resembling that of intrauterine pregnancy; in $10 \%$ of cases, the hCG course resembles that of an early miscarriage.

\section{Human chorionic gonadotropin (hCG)}

With a vital intrauterine pregnancy, the hCG level generally doubles within 48 hours, yet it sometimes rises by no more than $35 \%$ during this time even in normal cases. 
TABLE 3

The surgical and medical treatment ${ }^{* 1,2}$ of extrauterine pregnancy, modified from Pisarska et al. (8)

\begin{tabular}{l|l}
\hline Surgical treatment & Medical treatment (methotrexate)* \\
Indications & Indications \\
- rupture & $-\mathrm{hCG}<5000 \mathrm{IU} / \mathrm{L}$ \\
- hemodynamic instability & - rising $\mathrm{hCG}$ level in 48 hours \\
- symptoms (eg., pain) & - normal: hemoglobin, leukocytes, platelets, liver enzymes \\
- diagnostic laparoscopy & - diameter of gestational sac $<4 \mathrm{~cm}$
\end{tabular}

\begin{tabular}{l|l} 
- suspected heterotopic pregnancy & Absolute contraindications
\end{tabular}

- intrauterine pregnancy

- immune suppression

- hypersensitivity to methotrexate

- active lung disease

- active peptic ulcer disease

- clinically significant renal or hepatic dysfunction

- breastfeeding

- ruptured extrauterine pregnancy

- hemodynamic instability

\section{Relative contraindications}

- hCG > 5000 IU/L

- objection to blood transfusions

- follow-up not possible

\section{Surgical procedure}

organ- (tube-) preserving surgery

- salpingotomy

- segmental resection (partial salpingectomy)

- transampullary expression ("milk-out")

indications for an ablative procedure (salpingectomy)

- uncontrollable bleeding

- marked tubal destruction

- ipsilateral recurrence

- prior ipsilateral sterilization

\section{Follow-up}

- weekly hCG measurement until normalization

- persistent extrauterine pregnancy/trophoblastic tissue:

- re-laparoscopy

- drug therapy (methotrexate) when indicated

\section{Follow-up \\ - weekly hCG measurement until normalization \\ - persistent extrauterine pregnancy/trophoblastic tissue: \\ - repeat methotrexate administration \\ - surgery when indicated}

\footnotetext{
${ }^{\star 1}$ Used in: persistent tubal pregnancy or trophoblastic tissue, non-tubal extrauterine pregnancy/heterotopic pregnancies-combined approach: surgery and local drug application

${ }^{2}$ Whatever treatment is given, all non-sensitized Rh-negative patients must be given post-treatment anti-D prophylaxis, as after an intrauterine abortion.

hCG, human chorionic gonadotropin
}

Organ-preserving procedures include linear salpingotomy, transampullary expression, or segmental resection (partial salpingectomy with primary or secondary reanastomosis); the main objective is the removal of only the trophoblastic tissue. Improved diagnostic methods now enable most patients to have elective rather than emergency surgery (28). Laparoscopy is the gold standard of surgical treatment for extrauterine pregnancy (Figure 3)
$(28,29)$. Laparotomy is performed only if laparoscopy is not possible for technical, logistic, or medical reasons.

The advantages of laparoscopy over laparotomy are more rapid access to the abdomen, shorter surgery, less blood loss, less extensive postoperative adhesions, faster recovery, and lower costs of hospitalization and rehabilitation (30). Organ-preserving surgery is associated with higher rates of retention of trophoblastic tissue (4-15\%) (1).

\section{Surgical indications}
- rupture
- hemodynamic instability
- symptoms (e.g., pain)
- diagnostic laparoscopy
- suspected heterotopic pregnancy

\section{Indications for an ablative procedure}

- uncontrollable bleeding

- marked tubal destruction

- ipsilateral recurrence

- prior ipsilateral sterilization 


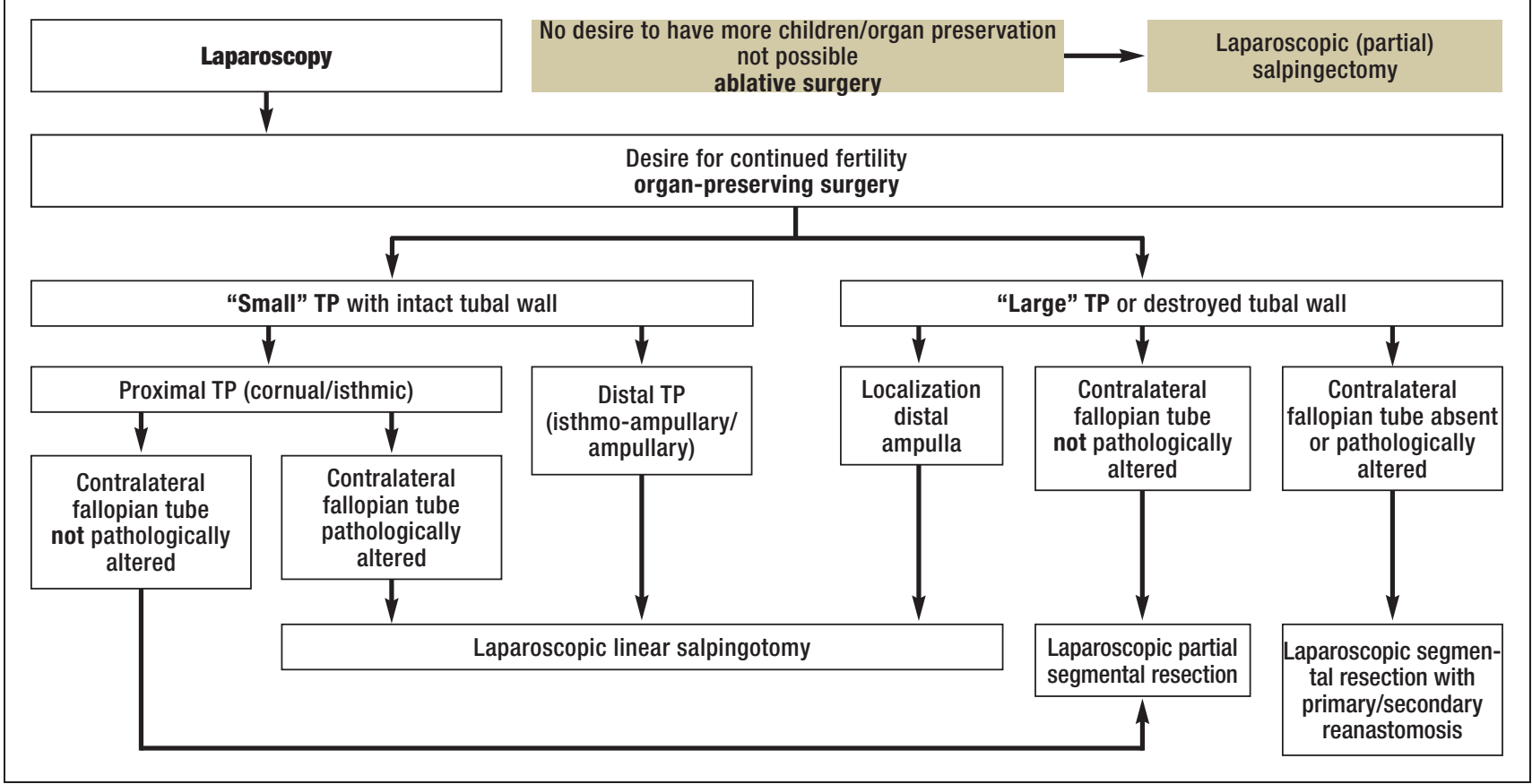

Algorithm for the individualized surgical treatment of tubal pregnancy (TP), modified from Wallwiener et al. (28)

The serum hCG level usually falls markedly on the first day after surgery, to less than half of its initial value (31).

\section{Preservation of tubal continuity (linear salpingotomy and transampullary expression) versus segmental resection}

In a linear salpingotomy (opening of the tube directly over the pregnancy with a straight incision, made with a monopolar needle), surgical trauma to the tube must be held to a minimum (27). In rare cases, the tubal pregnancy can be expressed through the ampulla ("milked out") with the aid of an atraumatic grasping forceps. This technique succeeds only in exceptional cases and should not be forced (27).

Segmental resection is indicated if a large tubal pregnancy has partly destroyed the ipsilateral tubal wall and the patient wishes to remain fertile even though the contralateral fallopian tube is diseased or absent (Figure 3) (28).

\section{Types of surgical procedure}

Laparoscopy is the gold standard of surgical treatment for extrauterine pregnancy. Laparotomy is performed only if laparoscopy is not possible for technical, logistic, or medical reasons.

\section{Organ-preserving procedures versus ablative surgery} (salpingectomy)

The first two multi-center, prospective, randomized trials comparing organ-preserving procedures with salpingectomy (the DEMETER and ESEP trials) were published in 2013 and 2014, respectively (32, 33) (Table 2).

The DEMETER trial revealed no significant difference in rates of intrauterine pregnancy within two years $(70 \%$ for organ-preserving surgery versus $64 \%$ for salpingectomy) (32). Similarly, the ESEP trial revealed no significant difference in rates of intrauterine pregnancy within three years (61\% for organ-preserving surgery versus $56 \%$ for salpingectomy) (33). A meta-analysis using data from both trials reinforced the conclusion that there is no difference in intrauterine pregnancy rates after the two types of procedure (33). However, it was not documented in the report of the ESEP trial whether the intrauterine pregnancies

\section{The advantages of laparoscopy over laparotomy}

More rapid access to the abdomen, shorter surgery, less blood loss, less extensive postoperative adhesions, faster recovery, and lower costs of hospitalization and rehabilitation. 
Methotrexate treatment protocols for extrauterine pregnancy

\begin{tabular}{|c|c|c|c|c|}
\hline Protocol & $\begin{array}{l}\text { Dosage, } \\
\text { mode of administration }\end{array}$ & $\begin{array}{l}\text { Timing of } \\
\text { administration }\end{array}$ & hCG measurement & Additional administration \\
\hline Single-dose & - MTX $50 \mathrm{mg} / \mathrm{m}^{2}$ BSA IM & - Day 1 & $\begin{array}{l}\text { - before treatment } \\
\text { - Day } 1 \\
\text { - Day } 4 \\
\text { - Day } 7\end{array}$ & $\begin{array}{l}\text { MTX } 50 \mathrm{mg} / \mathrm{m}^{2} \mathrm{BSA}, \text { IM on } \\
\text { Day } 7 \text { : } \\
\text { - if hCG drops by }<15 \% \\
\text { from Day } 4 \text { to Day } 7\end{array}$ \\
\hline Multi-dose & $\begin{array}{l}\text { - MTX } 1 \mathrm{mg} / \mathrm{kg} \mathrm{IM} \\
\text { - LEU } 0.1 \mathrm{mg} / \mathrm{kg} \text { IM }\end{array}$ & $\begin{array}{l}\text { - Day } 1 \text { MTX } \\
\text { - Day } 2 \text { LEU } \\
\text { possibly } \\
\text { - Day } 3 \text { MTX } \\
\text { - Day } 4 \text { LEU } \\
\text { possibly } \\
\text { - Day } 5 \text { MTX } \\
\text { - Day } 6 \text { LEU } \\
\text { possibly } \\
\text { - Day } 7 \text { MTX } \\
\text { - Day } 8 \text { LEU }\end{array}$ & $\begin{array}{l}\text { - before treatment } \\
\text { - Day } 1 \\
\text { - Day } 3 \\
\text { - Day } 5 \\
\text { - Day } 7\end{array}$ & $\begin{array}{l}2^{\text {nd }}, 3^{\text {rd }} \text {, or } 4^{\text {th }} \text { dose of MTX } \\
1 \mathrm{mg} / \mathrm{kg} \mathrm{IM} \text { followed by } \\
\text { LEU } 0.1 \mathrm{mg} / \mathrm{kg} \text { IM: } \\
\text { - if hCG drops by }<15 \% \text { of } \\
\text { prior hCG value }\end{array}$ \\
\hline
\end{tabular}

MTX, methotrexate; LEU, leucovorin; BSA, body surface area; hCG, human chorionic gonadotropin; IM, intramuscular

.Comments: a battery of laboratory tests (complete blood count with differential, liver enzymes, creatinine, blood-group determination, antibody search test) is obligatory before treatment; the serum hCG level must be rechecked every 7 days after the last dose of MTX until it becomes normal.

occurred in the ipsilateral or the contralateral fallopian tube; nor was there any specific discussion of the surprising finding that some ipsilateral tubal pregnancies arose despite prior salpingectomy (33).

The follow-up periods of these two trials were limited to two and three years, respectively, so the results should by no means be taken to justify the wider use of salpingectomy (33). Salpingectomy may adversely affect fertility over the long term: the rates of recurrent tubal pregnancy in both arms of both trials lay between $5 \%$ and $10 \%$ (33). Linear salpingectomy is preferable if the contralateral fallopian tube is diseased or if the patient has a history of infertility, because the cumulative intrauterine pregnancy rate is higher (34).

A regrettable common feature of all reports on the operative treatment of tubal pregnancy that have been published to date is that they contain no information on relevant variables including the experience and skill of the surgeons and the precise type of organ-preserving surgery that was performed (thus making it impossible to judge the postoperative continuity of the tubal segment). A survey in the Netherlands revealed that suboptimal surgical skills may explain the very low salpingotomy rate $(21 \%)$ in cases with contralateral tubal disease. Adequate clinical experience and very good surgical skills are essential prerequisites for the successful individualized treatment of tubal pregnancy (35).

The determination whether organ-preserving surgery is possible in the individual case is based on:

- the intensity of bleeding

- the size of the tubal pregnancy

- the degree of damage to the affected and contralateral fallopian tubes

- any prior history of infertility

- any prior tubal pregnancy

- the patient's wishes about future fertility

- the availability of assisted reproductive technology

- and, not least, the skill of the surgeon (2).

\section{Medical treatment}

The medical treatment of tubal pregnancy is an acceptable option only for very strict indications, and only when the patient can be safely expected to comply with the physician's recommendations (Table 3). Adequate data are available exclusively for systemic treatment with methotrexate. This drug has proven useful mainly

\section{Salpingotomy}

In a linear salpingotomy (opening of the tube directly over the pregnancy with a straight incision, made with a monopolar needle), surgical trauma to the tube must be held to a minimum.

\section{Pharmacotherapy (methotrexate)}

Adequate data are available for systemic treatment with methotrexate. This drug has proven useful mainly in the treatment of persistent trophoblastic tissue and of persistently elevated hCG values after conservative surgery. 

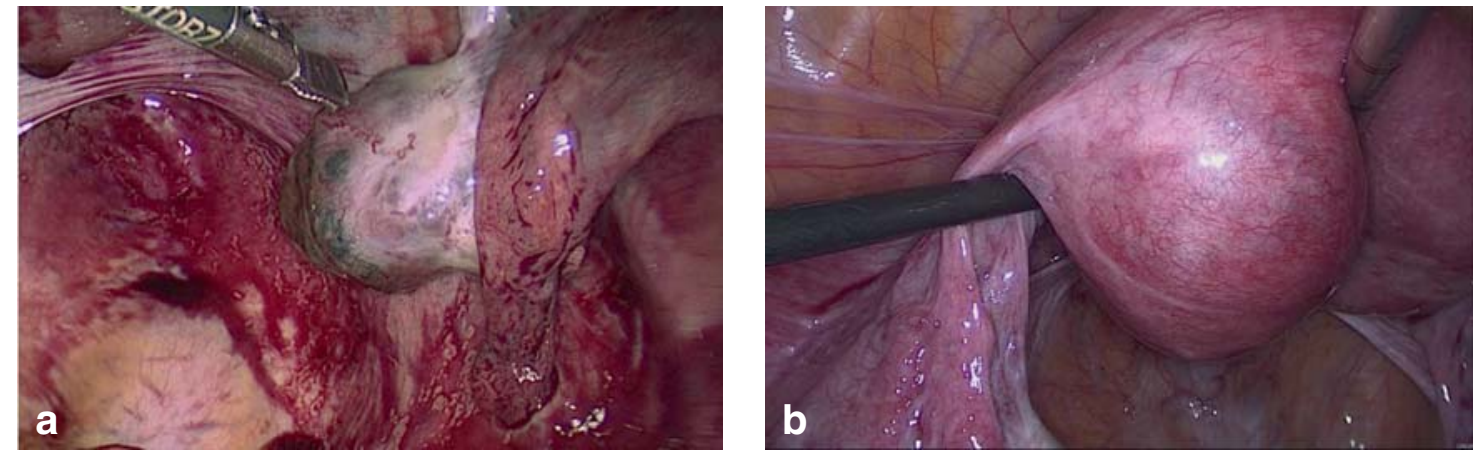

Figure 4: a) Right ovarian pregnancy, week $6+4$ of gestation; b) interstitial pregnancy in the left tubal angle in week $7+3$ of gestation.

in the treatment of persistent trophoblastic tissue and of persistently elevated hCG values after conservative surgery.

Methotrexate is a folic acid antagonist whose activity manifests itself chiefly in rapidly proliferating cells at the implantation site, particularly trophoblasts (36). Pharmacotherapy with systemically administered methotrexate is much less common in Germany than in the Englishspeaking countries because of the universal availability of gynecological care. The success rate of methotrexate treatment is variably reported in the literature, with rates ranging from $63 \%$ to $97 \%$; this is presumably due to the heterogeneity of patient groups and inclusion criteria, differences in methotrexate treatment protocols, and varying definitions of treatment response (32). The two most common protocols are the single-dose and the multi-dose protocol (Table 4) (37). A meta-analysis of nonrandomized studies revealed an $89 \%$ overall success rate of pharmacotherapy (1181 of 1327 patients treated); the multi-dose protocol was successful significantly more often than the single-dose protocol (93\% versus $88 \%$ ) but caused more side effects (37). The most common ones (nausea, vomiting, stomatitis, diarrhea, elevated liver enzymes) were usually mild (38). The rarer serious side effects included renal and hepatic damage, pneumonia, dermatitis, and pleuritis; these can be managed by adjusting the dose and duration of methotrexate treatment (36).

\section{Operative organ-preserving treatment versus pharmacotherapy}

A Cochrane analysis and three underpowered prospective randomized trials did not provide an adequate data base for a reliable comparison of fertility rates after tube-preserving surgery and drug treatment with methotrexate $(29,39)$. The most recent evaluation of the Auvergne registry revealed no significant difference in fertility rates (34). Only recently, in the context of the prospective, randomized DEMETER trial, Fernandez et al. reported no significant difference in 2-year fertility rates between women who had undergone these two types of treatment, with intrauterine pregnancy rates of $71 \%$ versus $67 \%$ (32) (Table 2). Comparisons of organpreserving surgery with pharmacotherapy are rendered less reliable by the paucity of prospective data and by the lack of information in any of the published studies about the type of organ-preserving surgery that was performed. These preliminary findings should therefore not be taken to justify the wider use of methotrexate treatment.

\section{Non-tubal and heterotopic extrauterine pregnancy}

Ectopic pregnancies can also be located in an ovary (Figure 4a), interstitially (in the intramyometrial portion of the fallopian tube) (Figure 4b), in the uterine horn, in the cervix, in the scar from a prior cesarean section, intramurally, and in the abdominal space. Non-tubal and heterotopic extrauterine pregnancies can pose a diagnostic and therapeutic challenge and are associated with higher morbidity (2). These rare conditions may necessitate a combined therapeutic approach involving both surgery and local drug application.

According to Begum et al., ovarian pregnancy (2\%) is the most common kind of non-tubal extrauterine pregnancy (40). Despite the high sensitivity of vaginal ultrasonography for extrauterine pregnancy, the diagnosis of ovarian pregnancy is often only made at surgery and may

\section{Prerequisites for successful surgical treatment}

Adequate clinical experience and very good surgical skills are essential prerequisites for the successful individualized treatment of tubal pregnancy.

\section{Single-dose and multi-dose protocols}

The two most common protocols are the single-dose and the multi-dose protocol. The multi-dose protocol has a higher success rate, but also more frequent side effects. 
necessitate partial or total ovariectomy. Cervical pregnancy is much rarer $(0.1 \%)$ and associated with high morbidity; it usually manifests itself with brisk vaginal bleeding (e1).

The increasing use of reproductive medical techniques is markedly raising the incidence of heterotopic pregnancy. Armbrust et al. described a heterotopic pregnancy in which one gestational sac was embedded in the uterotomy scar from a prior caesarean section and a second one lay within the uterus and was successfully maintained up to the $37^{\text {th }}$ week of gestation (e2). When the diagnosis is unclear, a non-tubal or heterotopic extrauterine pregnancy should always be considered.

\section{Conflict of interest statement}

The authors declare that no conflict of interest exists.

Manuscript submitted on 1 July 2015, revised version accepted on 26 August 2015.

Translated from the original German by Ethan Taub, M.D.

\section{REFERENCES}

1. Farquhar CM: Ectopic pregnancy. Lancet 2005; 366: 583-91.

2. Barnhart KT: Clinical practice. Ectopic pregnancy. N Engl J Med 2009; 361: 379-87.

3. Khan KS, Wojdyla D, Say L, Gülmezoglu AM, van Look PF: WHO analysis of causes of maternal death: a systematic review. Lancet 2006; 367: 1066-74.

4. Mikolajczyk RT, Kraut AA, Garbe E: Evaluation of pregnancy outcome records in the German Pharmacoepidemiological Research Database (GePaRD). Pharmacoepidemiol Drug Saf 2013; 22: 873-80.

5. Marion LL, Meeks GR: Ectopic pregnancy: History, incidence, epidemiology, and risk factors. Clin Obstet Gynecol 2012; 55: 376-86.

6. Ankum WM, Mol BW, van der Veen F, Bossuyt PM: Risk factors for ectopic pregnancy: a meta-analysis. Fertil Steril 1996; 65: 1093-9.

7. Mol BW, Ankum WM, Bossuyt PM, van der Veen F: Contraception and the risk of ectopic pregnancy: a meta-analysis. Contraception 1995; 52: 337-41.

8. Pisarska MD, Carson SA, Buster JE: Ectopic pregnancy. Lancet 1998; 351: 1115-20.

9. Malacova E, Kemp A, Hart R, Jama-Alol K, Preen DB: Long-term risk of ectopic pregnancy varies by method of tubal sterilization: a whole-population study. Fertil Steril 2014; 101: 728-34.

10. Benagiano G, Gabelnick H, Farris M: Contraceptive devices: intravaginal and intrauterine delivery systems. Expert Rev Med Devices 2008; 5: 639-54.

11. Maymon R, Shulman A: Controversies and problems in the current management of tubal pregnancy. Hum Reprod Update 1996; 2 : $541-51$.

\section{Ovarian pregnancy}

The diagnosis of ovarian pregnancy is often only made at surgery and may necessitate partial or total ovariectomy.
12. Perkins KM, Boulet SL, Kissin DM, Jamieson DJ: Risk of ectopic pregnancy associated with assisted reproductive technology in the United States, 2001-2011. Obstet Gynecol 2015; 125: 70-8.

13. Shaw JL, Wills GS, Lee KF, et al.: Chlamydia trachomatis infection increases fallopian tube PROKR2 via TLR2 and NFB activation resulting in a microenvironment predisposed to ectopic pregnancy. Am J Pathol 2011; 178: 253-60.

14. Kirk E, Bottomley C, Bourne T: Diagnosing ectopic pregnancy and current concepts in the management of pregnancy of unknown location. Hum Reprod Update 2014; 20: 250-61.

15. Sawyer E, Ofuasia E, Ofili-Yebovi D, Helmy S, Gonzalez J, Jurkovic $\mathrm{D}$ : The value of measuring endometrial thickness and volume on transvaginal ultrasound scan for the diagnosis of incomplete miscarriage. Ultrasound Obstet Gynecol 2007; 29: 205-9.

16. Barnhart K, van Mello NM, Bourne T, et al.: Pregnancy of unknown location: a consensus statement of nomenclature, definitions, and outcome. Fertil Steril 2011; 95: 857-66.

17. Kirk E, Papageorghiou AT, Condous G, Tan L, Bora S, Bourne T: The diagnostic effectiveness of an initial transvaginal scan in detecting ectopic pregnancy. Hum Reprod 2007; 22: 2824-8.

18. Crochet JR, Bastian LA, Chireau MV: Does this woman have an ectopic pregnancy?: the rational clinical examination systematic review. JAMA 2013; 309: 1722-9.

19. Frates MC, Doubilet PM, Peters HE, Benson CB: Adnexal sonographic findings in ectopic pregnancy and their correlation with tubal rupture and human chorionic gonadotropin levels. J Ultrasound Med 2014; 33: 697-703.

20. van Mello NM, Mol F, Opmeer BC, et al.: Diagnostic value of serum hCG on the outcome of pregnancy of unknown location: a systematic review and meta-analysis. Hum Reprod Update 2012; 18: 603-617.

21. Seeber BE, Sammel MD, Guo W, Zhou L, Hummel A, Barnhart KT: Application of redefined human chorionic gonadotropin curves for the diagnosis of women at risk for ectopic pregnancy. Fertil Steril 2006; 86: 454-9.

22. Condous G, Kirk E, van Calster B, van Huffel S, Timmerman D, Bourne T: Failing pregnancies of unknown location: a prospective evaluation of the human chorionic gonadotrophin ratio. BJOG 2006; 113: 521-7.

23. Kirk E, Condous G, van Calster B, van Huffel S, Timmerman D, Bourne T: Rationalizing the follow-up of pregnancies of unknown location. Hum Reprod 2007b; 22: 1744-50.

24. van Calster $B$, Abdallah $Y$, Guha $S$, et al.: Rationalizing the management of pregnancies of unknown location: temporal and external validation of a risk prediction model on 1962 pregnancies. Hum Reprod 2013; 28: 609-16.

25. Mol BW, Lijmer JG, Ankum WM, van der Veen F, Bossuyt PM: The accuracy of single serum progesterone measurement in the diagnosis of ectopic pregnancy: a meta-analysis. Hum Reprod 1998; 13: $3220-7$.

26. van Mello NM, Mol F, Verhoeve HR, et al.: Methotrexate or expectant management in women with an ectopic pregnancy or pregnancy of unknown location and low serum hCG concentrations? A randomized comparison. Hum Reprod 2013; 28: 60-7.

27. Wallwiener D, Becker S: Atlas of Gynecologic Surgery. Stuttgart: Thieme $4^{\text {th }}$ edition 2013.

28. Wallwiener D, Pollmann D, Gauwerky J, Sohn C, Bastert G: Operative treatment of tubal pregnancy. In: Bastert G, Wallwiener (eds.): Lasers in gynecology. Berlin, Heidelberg: Springer 1992.

29. Hajenius PJ, Mol F, Mol BW, Bossuyt PM, Ankum WM, van der Veen F: Interventions for tubal ectopic pregnancy. Cochrane Database Syst Rev 2007; (1): CD000324.

30. Murphy AA, Nager CW, Wujek JJ, Kettel LM, Torp VA, Chin HG: Operative laparoscopy versus laparotomy for the management of ectopic pregnancy: a prospective trial. Fertil Steril 1992; 57: 1180-5. 
31. Spandorfer SD, Sawin SW, Benjamin I, Barnhart KT: Postoperative day 1 serum human chorionic gonadotropin level as a predictor of persistent ectopic pregnancy after conservative surgical management. Fertil Steril 1997; 68: 430-4.

32. Fernandez H, Capmas P, Lucot JP, Resch B, Panel P, Bouyer J; GROG. Fertility after ectopic pregnancy: the DEMETER randomized trial. Hum Reprod 2013; 28: 1247-53.

33. Mol F, van Mello NM, Strandell A, et al.: Salpingotomy versus salpingectomy in women with tubal pregnancy (ESEP study): an open-label, multicentre, randomised controlled trial. Lancet 2014; 383: 1483-9.

34. Capmas P, Bouyer J, Fernandez H: Treatment of ectopic pregnancies in 2014: new answers to some old questions. Fertil Steril 2014; 101: 615-20

35. D'Hooghe T, Tomassetti C: Surgery for ectopic pregnancy: making the right choice. Lancet 2014; 383: 1444-5.

36. Bachman EA, Barnhart K: Medical management of ectopic pregnancy: a comparison of regimens. Clin Obstet Gynecol 2012; 55 440-7.

37. Practice Committee of the American Society for Reproductive Medicine. Medical treatment of ectopic pregnancy: a committee opinion. Fertil Steril 2013; 100: 638-44.

38. Barnhart KT, Gosman G, Ashby R, Sammel M: The medical management of ectopic pregnancy: a meta-analysis comparing "single dose" and "multidose" regimens. Obstet Gynecol 2003; 101: 778-84.

39. Dias Pereira G, Hajenius PJ, Mol BW, et al.: Fertility outcome after systemic methotrexate and laparoscopic salpingostomy for tubal pregnancy. Lancet 1999; 353: 724-5.

40. Begum J, Pallavee P, Samal S: Diagnostic dilemma in ovarian pregnancy: a case series. J Clin Diagn Res 2015; 9: QR01-3.

\section{Corresponding author}

Prof. Dr. med. Florin-Andrei Taran

Department für Frauengesundheit

Universitätsklinikum Tübingen

Calwerstr. 7,

72076 Tübingen, Germany

florin-andrei.taran@med.uni-tuebingen.de

Supplementary material:

For eReferences please refer to:

www.aerzteblatt-international.de/ref4115

\section{Further information on CME}

This article has been certified by the North Rhine Academy for Postgraduate and Continuing Medical Education. Deutsches Ärzteblatt provides certified continuing medical education (CME) in accordance with the requirements of the Medical Associations of the German federal states (Länder). CME points of the Medical Associations can be acquired only through the Internet, not by mail or fax, by the use of the German version of the CME questionnaire. See the following website: cme.aerzteblatt.de.

Participants in the CME program can manage their CME points with their 15-digit "uniform CME number" (einheitliche Fortbildungsnummer, EFN). The EFN must be entered in the appropriate field in the cme.aerzteblatt.de website under "meine Daten" ("my data"), or upon registration. The EFN appears on each participant's CME certificate.

This CME unit can be accessed until 3 January 2016, and earlier CME units until the dates indicated:

- "Transfusion of Packed Red Blood Cells" (Issue 29-30/2015) until 11 October 2015 ,

- "The Investigation and Treatment of Female Pelvic Floor Dysfunction" (Issue 33-34/2015) until 8 November 2015,

- "The Diagnosis and Treatment of Optic Neuritis" (Issue 37/2015) until 6 December 2015. 


\section{Please answer the following questions to participate in our certified Continuing Medical Education program. Only one answer is possible per question. Please select the most appropriate answer.}

Question 1

What percentage of pregnancies are extrauterine?
a) $0.1-1.1 \%$
b) $1.3-2.4 \%$
c) $2.5-3.6 \%$
d) $3.7-4.8 \%$
e) $4.9-6.0 \%$

\section{Question 2}

What ultrasonographic findings are consistent with a pseudogestational sac?

a) an adnexal mass, generally not involving the ovary, that is round and echogenic (blob sign)

b) a small fluid collection in the uterine cavity

c) an echogenic periphery and a round, non-echogenic interior (bagel sign)

d) an echogenic fluid collection in Douglas' pouch

e) non-echogenic fluid covering the fundus and extending into Morison's pouch

\section{Question 3}

What is the role of the serum progesterone level in the diagnostic evaluation of extrauterine pregnancy?

a) A single measurement can definitively confirm the diagnosis.

b) The course of the rising progesterone level in 48 hours is decisive.

c) If the hCG test is inconclusive, progesterone measurement can rule out a non-intact pregnancy with high probability.

d) If the progesterone level does not fall, this indicates a vital extrauterine pregnancy.

e) In intrauterine pregnancies, the progesterone level is double the hCG level.

\section{Question 4}

Which of the following confers a high risk of extrauterine pregnancy?
a) prior appendicitis
b) a less than six-month interval between two pregnancies
c) oral contraceptive use
d) teenage pregnancy
e) prior tubal surgery

\section{Question 5}

Which of the following is an indication for tube-preserving surgery?
a) ipsilateral recurrence
b) only mild bleeding
c) prior ipsilateral sterilization
d) hemodynamic instability
e) active lung disease

Question 6

Which of the following is an absolute contraindication for systemic methotrexate treatment for extrauterine pregnancy?

a) a rising hCG level within 48 hours

b) a gestational sac measuring less than $4 \mathrm{~cm}$ in diameter

c) an hCG level below $5000 \mathrm{IU} / \mathrm{L}$

d) the patient's objection to blood transfusions

e) clinically significant hepatic dysfunction

\section{Question 7}

Which of the following is an advantage of laparoscopy over laparotomy in the surgical treatment of extrauterine pregnancy?

a) longer operations

b) better histologically based staging

c) simplified emergency medical care

d) more likely persistence of trophoblastic tissue

e) fewer postoperative adhesions

Question 8

What is the common cardinal finding in ectopic pregnancy and pregnancy of unknown location?

a) unusually intense vaginal bleeding

b) primary amenorrhea

c) lack of evidence of an intrauterine pregnancy on ultrasound

d) aching pelvic pain

e) tachycardia

\section{Question 9}

A 32-year-old woman with a tubal pregnancy seeks your advice. She wants to remain fertile. Ultrasonography reveals a "small" tubal pregnancy with an intact tubal wall. The contralateral tube appears healthy. What surgical method can be considered?

a) transampullary expression

b) secondary reanastomosis

c) laparoscopic linear salpingotomy

d) laparoscopic partial tubal resection

e) the Lichtenstein procedure

Question 10

A 42-year-old woman is evaluated for a suspected extrauterine pregnancy and a tubal pregnancy is found, despite a prior sterilizing procedure on the the ipsilateral fallopian tube. What is the correct treatment?

a) partial salpingectomy

b) weekly follow-up until normalization

c) methotrexate therapy

d) salpingostomy

e) ablative salpingectomy 


\section{Supplementary material to:}

\section{The Diagnosis and Treatment of Ectopic Pregnancy}

by Florin-Andrei Taran, Karl-Oliver Kagan, Markus Hübner, Markus Hoopmann, Diethelm Wallwiener, Sara Brucker

Dtsch Arztebl Int 2015; 112: 693-704. DOl: 10.3238/arztebl.2015.0693

\section{EREFERENCES}

e1. Fylstra DL: Cervical pregnancy: 13 cases treated with suction curettage and balloon tamponade. Am J Obstet Gynecol 2014; 210: 581 .e1-5.

e2. Armbrust R, Krätschell R, Henrich W, David M: Operative therapy for heterotopic scar pregnancy and successful birth of the intrauterine foetus - case report and review of the literature. Geburtshilfe Frauenheilkd 2015; 75: 384-88. 